\title{
Self-controlled responses to COVID-19: Self-control and uncertainty predict responses to the COVID-19 pandemic
}

\author{
Jordan E. Rodriguez ${ }^{1}$ (D) $\cdot$ Hayden L. Holmes ${ }^{1} \cdot$ Jessica L. Alquist ${ }^{1} \cdot$ Liad Uziel $^{2} \cdot$ Alec J. Stinnett $^{1}$ \\ Accepted: 1 July 2021 / Published online: 10 July 2021 \\ (C) The Author(s), under exclusive licence to Springer Science+Business Media, LLC, part of Springer Nature 2021
}

\begin{abstract}
Two online studies (Total $N=331$ ) tested the hypothesis that individual differences in self-control and responses to uncertainty would predict adherence to Centers for Disease Control and Prevention (CDC, 2020a) guidelines, reported stockpiling, and intentions to engage in hedonic behavior in response to the COVID-19 pandemic. Trait self-control $(b=0.27, p=.015)$, desire for self-control (Study 1: $b=0.28, p=.001$; Study 2: $b=0.27, p=.005$ ), and cognitive uncertainty $(b=0.73, p<.001)$ predicted more CDC adherence. State self-control (Study 1: $b=-0.15, p=.012$; Study 2: $b=-0.26, p<.001$ ) predicted less stockpiling, whereas emotional uncertainty $(b=0.56, p<.001)$ and cognitive uncertainty $(b=0.61, p<.001)$ predicted more stockpiling. State self-control $(b=-0.18, p=.003)$ predicted less hedonic behavior, whereas desire for self-control $(b=0.42, p<.001)$ and emotional uncertainty $(b=0.26, p=.018)$ predicted more hedonic behavior. Study 2 (pre-registered) also found that emotional uncertainty predicted more stockpiling and hedonic behavior for participants low in state self-control (stockpiling: $b=-0.31, p<$ .001 ; hedonic behavior: $b=0.28, p=.025$ ), but not for participants high in state self-control (stockpiling: $b=0.03, p=.795$; hedonic behavior: $b=-0.24, p=.066$ ). These findings provide evidence that some forms of self-control and uncertainty influenced compliance with behavioral recommendations during the COVID-19 pandemic.
\end{abstract}

Keywords Self-control $\cdot$ COVID-19 $\cdot$ Health behaviors $\cdot$ Uncertainty

In early 2020, people were urged to take drastic precautions to reduce the spread of a new virus. Soon after, the World Health Organization (WHO, 2020) announced that the outbreak of the Coronavirus disease 2019 (COVID-19) would be characterized as a pandemic. People immediately began buying large amounts of food staples, personal items, and cleaning supplies, leaving some store shelves empty for weeks (Guynn, 2020; Jones \& Tyko, 2020). The U.S. Centers for Disease Control and Prevention (CDC, 2020a) published guidelines to try to prevent the spread of the virus, including wearing a face covering and maintaining a distance of at least six feet from others. Containment of the spread of the virus depended in part on individual compliance. Individuals had to choose between the slight discomfort of wearing a face covering when in public, or taking a greater risk of becoming infected or infecting others. Grocery shoppers were faced with the

Jordan E. Rodriguez

jordan.rodriguez@ttu.edu

1 Texas Tech University, Box 42051, Lubbock, TX 79409, USA

2 Bar-Ilan University, Ramat-Gan, Israel decision to buy only what they needed, or to stock up on common goods, potentially creating shortages and leaving people in need. Several national holidays occurred in the U.S., enticing Americans to celebrate in large gatherings and ignore social distancing guidelines at the risk of creating a "superspreader" event.

These dilemmas created conflicts in which individuals must choose between their personal interest and the good of society, which can be resolved through the use of self-control. Self-control may make it easier for individuals to follow the guidelines surrounding COVID-19. We predicted that selfcontrol and dispositional responses to uncertainty would be associated with adherence to CDC guidelines, stockpiling, and indulging in hedonic behaviors.

\section{Self-Control and COVID-19 Response}

Self-control is broadly defined as one's likelihood of prioritizing long-term goals when they conflict with immediate goals or desires (de Ridder et al., 2018; Fujita, 2011). Selfcontrol is necessary to meet many goals, regardless of whether those goals were established by the self or by society (Vohs \& 
Baumeister, 2017). Individuals with high self-control engage in healthier behaviors, such as less substance abuse and higher likelihood of exercising, than individuals low in self-control (Crescioni et al., 2011; Hagger et al., 2009; Vohs \& Baumeister, 2017). Individuals with high self-control are also more willing to help others, adhere to social norms, and make prosocial decisions than those with low self-control (DeWall et al., 2008; Tian et al., 2018; Vohs \& Baumeister, 2017). An individual's overall tendency to choose long-term goals over short-term goals is considered trait self-control (Tangney et al., 2004). An individual's likelihood of choosing behaviors that support a long-term goal over behaviors that support a short-term goal at a point in time is considered state selfcontrol (Twenge et al., 2004). Although state self-control is sometimes thought of as "in the moment" self-control, it is somewhat stable over short periods of time. Experience sampling data found that over the course of the week, state selfcontrol varied relatively little within an individual (Zhang et al., 2018). Whereas trait self-control reflects one's general level of self-control, state self-control may be more sensitive to people's feelings of control during a recently-declared pandemic.

The COVID-19 pandemic presented individuals with many self-control conflicts; people were asked to stay at home and to not gather at social events, not to buy food or household items in excess, and to partake in unpracticed behaviors previously acknowledged as atypical, such as keeping a social distance from people and wearing face coverings in public. Following these guidelines required self-control in that individuals had to override the desire to do something immediately rewarding or desirable (take off the uncomfortable mask, hug a friend) in order to pursue the long-term goal of preserving the health and well-being of themselves and those around them. Indeed, recent research has shown that adherence to pandemic-related health behaviors is self-control demanding (Wolff et al., 2020), and is also associated with generally negative and aversive experiences (Brooks et al., 2020). Wolff et al. (2020) found that high trait self-control was directly related to social distancing adherence, and it also buffered the effect of perceived difficulty of following social distancing guidelines on adherence.

Due to a potential risk of food, health, and medical supply shortages, American residents were instructed not to buy more than they needed at the beginning of the pandemic (Executive Order No. 13910, 2020). Research on stockpiling behaviors during the pandemic has found that individuals characterized by the Dark Triad traits (i.e., psychopathy, Machiavellianism, and narcissism), as well as collective narcissism (the feeling that one's group is superior to other groups), engaged in more hoarding (Nowak et al., 2020). Not only was buying much more than one typically bought considered to be insensitive to other shoppers, but stockpiling medical supplies or personal protective equipment could potentially leave hospitals and treatment centers in dire need during this time. In line with prior work on self-control and COVID-19 (Martarelli \& Wolff, 2020; Wolff et al., 2020), we predicted that both trait and state self-control would be related to people's likelihood of following COVID-19 guidelines, which include adhering to $\mathrm{CDC}$ recommended health behaviors and avoiding stockpiling.

Pandemic-containment behaviors are simultaneously aversive and self-control demanding, which can further lead to a reduction in willingness to exert future efforts of self-control (Brooks et al., 2020; Martarelli \& Wolff, 2020; Wolff \& Martarelli, 2020). After using self-control to carry out these health behaviors, people may indulge in hedonic behaviors to make themselves feel better. Hedonic behaviors are activities that are inherently enjoyable or pleasurable. When self-control is low, people will tend to indulge in more inherently enjoyable behaviors (Baumeister \& Heatherton, 1996). We predicted that low state self-control would be associated with more indulgence in hedonic behaviors during the COVID-19 pandemic.

In addition to the amount of self-control people have, research has shown that the degree to which people wish to have more self-control can also predict behavior (Uziel \& Baumeister, 2017). Desire for self-control is a wish for more self-control which rests on the belief that one does not have enough self-control to meet necessary demands. Desire for self-control is theoretically distinct from the amount of selfcontrol people believe they have (see Uziel \& Baumeister, 2017, for review). Even participants who report moderate to high levels of self-control still report wanting more control. Counterintuitively, this desire then impairs future efforts of self-control as the person realizes they are not capable of meeting current demands. In previous research, wanting more self-control (measured or manipulated) in the face of difficult challenges led to a sense of reduced self-efficacy, which impaired performance on future efforts of self-control (Uziel \& Baumeister, 2017). Given that the desire for self-control arises when one recognizes that they have a need for more self-control, a higher desire for self-control should appear during situations in which people feel they need more self-control to carry out or avoid certain actions. Due to this ironic effect of desire for self-control, we expected a high desire for selfcontrol to be associated with more stockpiling and indulgence in hedonic behaviors, and fewer CDC-recommended behaviors.

\section{Uncertainty and COVID-19 Response}

Uncertainty is the awareness of a lack of knowledge (Anderson et al., 2019). Sources of uncertainty can stem from the randomness or unpredictability of future events, as well as the perceived ambiguity and complexity of that information. 
The International Monetary Fund estimates that global economic and political uncertainty stemming from the COVID19 pandemic is at an unprecedented high, three times the size than during the previous 2002-2003 severe acute respiratory syndrome (SARS) outbreak (International Monetary Fund; Ahir et al., 2020). Most of what was known about the virus was probabilistic (National Safety Council, 2020). Further, the National Safety Council reported being unable to quantify the odds of dying from COVID-19 due to rapidly changing mortality trends. Even though minimal amounts of uncertainty may not be as aversive, prolonged or chronic uncertainty is considered to be a threatening event (Anderson et al., 2019). Due to the uncertainty surrounding the pandemic, we predicted that individual differences in people's responses to uncertainty would interact with state self-control to predict their behavioral responses to COVID-19.

Early theorizations of coping with uncertainty posited that responses to threatening or stressful situations are appraised to assess the situation, which in turn informs coping strategies to manage the stressor (Lazarus \& Folkman, 1984). These strategies include emotionfocused coping, which involves regulating one's emotions and affective response to the situation, and problem-focused coping, which involves changing or managing the source of the stress or situation (Lazarus \& Folkman, 1984). Building from this theory, Greco and Roger (2001) identified individual differences in the degree to which people respond to uncertainty emotionally and cognitively. These traits are measured on separate scales, and an individual can be high on one, both, or neither. Emotional responses to uncertainty involve experiencing uncertainty as emotionally threatening, which leads to anxiety and negative affect. Cognitive responses to uncertainty involve coping with uncertainty by planning ahead and taking action to reduce or avoid ambiguity (Greco \& Roger, 2001). Theoretically similar to an emotional response to uncertainty is intolerance of uncertainty, they are both driven by perceiving ambiguous and uncertain situations as threatening (Rosen et al., 2014). Recent research found a positive association between intolerance of uncertainty and COVID-19-related health anxiety (Tull et al., 2020). If information about a situation is perceived as ambiguous, people who respond with more emotional uncertainty will have a more difficult time coping and regulating their emotions. People who respond with more cognitive uncertainty will cope by taking action in order to reduce uncertainty.

Stress from the COVID-19 pandemic was relatively high on a global level (Xiong et al., 2020). As such, coping with stress was heavily emphasized in the U.S., through both conventional (e.g., therapy, helplines) and unconventional (e.g., 'treating yourself') methods (CDC, 2020b; Gran, 2020). Hedonic consumption has been viewed as compensating for personal discomfort through buying hedonic or materialistic goods to reduce that discomfort (Mandel et al., 2017). Indeed, recent research found that pandemic-related uncertainty increases consumers' tendencies to compensate by spending more money on things they want but do not need (Pomerance et al., 2020). Additionally, a perceived lack of control stemming from the pandemic increased consumers' materialistic and impulsive tendencies (Li et al., 2020b). Taken together, this research suggests that uncertainty surrounding the COVID-19 pandemic increases anxiety and may motivate hedonic consumption, although the exact mechanisms are unclear.

Given that an emotional response to uncertainty is characterized by negative affect, participants with a higher emotional response to uncertainty should engage in more stockpiling and hedonic activities to feel better. Participants who have a higher cognitive response to uncertainty should follow CDC guidelines and enact more preventative health behaviors, insofar as a cognitive response to uncertainty is marked by problemfocused actions that reduce uncertainty.

\section{Self-Control and Emotional Responses to Uncertainty}

Previous research has shown that the effect of individual differences is stronger when self-control is low. Low state selfcontrol among those with high anxiety leads to increased worrying, impaired cognitive performance on academic tasks, and impaired attention regulation (Bertrams et al., 2013; Englert \& Bertrams, 2015). Recent research has found that high selfcontrol buffers the impact of a negative appraisal of the COVID-19 pandemic, such that the correlation between perceived severity of the pandemic and mental health problems decreased as participants' self-control ability increased ( $\mathrm{Li}$ et al., 2020a). Global uncertainty was at an all-time high during the COVID-19 pandemic (International Monetary Fund; Ahir et al., 2020). How people cope with this uncertainty depends in part on their emotional or cognitive dispositional response to uncertainty. However, people's ability to control their behavior in a given time period (state self-control) may also be protective against dispositional traits. Thus, we expected the relationship between emotional responses to uncertainty, stockpiling behaviors, and hedonic behaviors to be stronger for participants lower in state self-control than participants higher in self-control.

\section{Overview of the Present Research}

The present research was designed to test the hypothesis that, in a sample of U.S. participants, high trait and state selfcontrol would predict better adherence to the guidelines 
surrounding COVID-19. We also predicted that cognitive response to uncertainty would be associated with CDC adherence, and emotional uncertainty would be associated with more stockpiling and indulgence in hedonic behaviors. Additionally, we tested the hypothesis that for individuals with high state self-control the association between emotional uncertainty and behavior would be weaker than for individuals with low state self-control. In both studies, we measured participants' compliance with CDC-recommended health behaviors and stockpiling. Health behaviors were measured by asking how much participants engaged in certain behaviors that, according to the $\mathrm{CDC}$, helped to protect oneself and others (CDC, 2020a). We measured stockpiling by asking participants how much of various items they had bought since the outbreak of COVID-19 compared to how much they usually buy. In Study 2, we were interested in how self-control and responses to emotional uncertainty predict engagement in hedonic behaviors. We asked participants to self-report on how they would spend unexpected time as a measure of indulgence in hedonic behavior.

An instructional attention check was included in both studies (embedded in the state self-control measure), in which the question item instructed participants to select "a little not true" as their answer; those who did not select that response were excluded from all analyses in both studies. All main effects were analyzed using mean-centered scores of each predictor in individual linear regression analyses in both studies. The primary assumptions for all analyses were met. For exploratory purposes, we also assessed several other variables, including political orientation, personality trait type, and social desirability. Details regarding these exploratory analyses can be found in Supplemental Materials.

Data were collected at the front-end of the pandemic (midApril), after the pandemic was officially declared (WHO, 2020). Studies 1 and 2 were run concurrently and designed by different researchers, which is the reason the studies do not use the exact same measures (e.g. measuring trait and state self-control in Study 1, but measuring just state self-control in Study 2). Both studies complied with ethical guidelines and were approved by the institutional review board. All participants provided informed consent before participating, and were debriefed, thanked, and compensated upon completion. Study 2 was pre-registered at https://aspredicted.org/blind. php? $=\mathrm{d} 2 \mathrm{j} 24 \mathrm{k}$; https://aspredicted.org/x4hi5.pdf.

\section{Study 1}

Study 1 tested the hypothesis that trait and state self-control would respectively predict more CDC adherence and less stockpiling. Study 1 also tested the hypothesis that high desire for self-control would predict less CDC adherence and more stockpiling.

\section{Method}

\section{Participants}

An a priori power analysis (GPower; Erdfelder et al., 1996) was used to determine the number of participants needed to detect a small-medium effect size for self-control on pandemic-related responses. Using $\alpha=.05$ (one-tailed), it was determined that a minimum of 138 participants were required to obtain an effect size of $r=.21$ in a correlation test with $80 \%$ power. This effect size estimate was based on a meta-analysis of the effect of trait self-control on selfreported behaviors (de Ridder et al., 2012). We added $10 \%$ of this total $(N=152)$, following a lab standard to account for anticipated omissions due to completion and attention check failures. U.S. residents were recruited for an online study via TurkPrime, a research platform associated with Amazon's Mechanical Turk (MTurk; cf. Buhrmester et al., 2011; TurkPrime; see Litman et al., 2017). Of the 152 participants recruited, 4 started the survey but did not complete it, and 10 were excluded due to failing the attention check question embedded in the state self-control measure. Thus, analyses were performed on the final sample $(N=138 ; 80$ men, 57 women, 1 agender; $\left.M_{\mathrm{age}}=37.1, S D=13.0\right)$.

\section{Materials}

\section{Adherence to CDC Health Recommendations Questionnaire} Participants were asked the extent to which they adhered to each of nine behaviors recommended on the $\mathrm{CDC}$ website in response to the outbreak of COVID-19 (CDC, 2020a). Participants were asked to, "indicate how much you have done each of the following activities since, or in response to, the outbreak of COVID-19 (the novel coronavirus)." Anchors for the scale were 1 (Less than usual) to 4 (Usual amount) to 7 (More than usual) and an "N/A" option, which was coded as missing data. Sample items include "Social distancing" and "Using hand sanitizer" (see Appendix 1 for all items). Responses on the scale showed high internal consistency, Cronbach's $\alpha=.86$.

Stockpiling Behaviors Questionnaire Participants were asked the extent to which they bought each of 13 products since the outbreak of COVID-19. The products included were based on necessary grocery and household items, as well as items that were discussed in the media as being bought at high levels, such as toilet paper, firearms and ammunition, and cleaning or disinfectant supplies (Guynn, 2020; Jones \& Tyko, 2020; Oppel Jr., 2020). Participants were asked to "indicate how much of each product you have bought since, or in response to, the outbreak of COVID-19 (the novel coronavirus)." Anchors for the scale were 1 (Less than usual) to 4 (Usual amount) to 7 (More than usual) and an "N/A" option, which 
was coded as missing data. Sample items include "Toilet paper" and "Medical masks" (see Appendix 2 for all items); Cronbach's $\alpha=.84$.

Trait Self-Control Scale (TSCS; Tangney et al., 2004) The brief version of the TSCS (Cronbach's $\alpha=.81$ ) was used to assess self-reported levels of trait self-control. The TSCS is a 13item, Likert-type scale with anchors of 1 (Not at all like me) to 5 (Very much like me). Sample items include, "I am good at resisting temptation" and "I refuse things that are bad for me."

State Self-Control Scale (SSCS; Twenge et al., 2004) The SSCS was designed to assess how much self-control participants feel they have at that moment. The SSCS (Cronbach's $\alpha=.95$ ) is a 25-item, Likert-type questionnaire with anchors of 1 (Not true) to 7 (Very true). Sample items include, "I feel discouraged" (reverse-coded) and "A new challenge would appeal to me right now."

Marlowe-Crowne 2(10) Social Desirability Scale (M-C 2(10); Strahan \& Gerbasi, 1972) The M-C 2(10) was designed to assess a person's levels of social desirability or wanting to enact socially acceptable behaviors. The M-C 2(10) is a 10item, true $(1)$ /false $(0)$ questionnaire with higher scores indicating higher social desirability (Cronbach's $\alpha=.62$ ). Examples items include, "I never hesitate to go out of my way to help someone in trouble" and "I have never intensely disliked anyone."

Desire for Self-Control Scale (DSCS; Uziel \& Baumeister, 2017) The DSCS is designed to assess a person's motivation to have more self-control. The DSCS (Cronbach's $\alpha=.91$ ) is an 8item, Likert-type questionnaire with anchors of 1 (Strongly disagree) to 5 (Strongly agree). Sample items include, "I want to be more self-disciplined" and "I want to have more control over my feelings."

\section{Procedure}

Participants completed the stockpiling behaviors and CDC adherence questionnaires in a random order. Next, the trait self-control scale, state self-control scale, social desirability scale, and desire for self-control scale were presented to participants in a random order, followed by a demographics questionnaire.

\section{Analytic Approach}

Simple regressions were used to test whether trait self-control, state self-control, and desire for self-control predict CDC adherence and stockpiling, respectively. To distinguish desire for self-control from trait and state self-control, the relationships between desire for self-control and the outcome variables were analyzed controlling for trait self-control and state self-control (Uziel \& Baumeister, 2017). Additionally, because self-control is a socially desirable characteristic and people are often motivated to report that they have high selfcontrol, social desirability was controlled for across all analyses. Exploratory analyses for the main effect of social desirability on responses can be found in Supplemental Materials; all analyses were conducted using SPSS 26.0.

\section{Results}

See Table 1 for means, standard deviations, and correlations for all variables.

\section{CDC Adherence}

Trait self-control significantly predicted more CDC adherence, $t(137)=2.45, p=.015, b=0.27,95 \%$ CI $[0.05,0.49]$, even when controlling for social desirability, $t(137)=2.00, p$ $=.048, b=0.24,95 \%$ CI $[0.001,0.47]$. Likewise, state selfcontrol significantly predicted more CDC adherence, $t(137)=$ $3.10, p=.002, b=0.26,95 \%$ CI [0.07, 0.29] (see Figure 1), even when controlling for social desirability, $t(137)=2.78, p$ $=.006, b=0.24,95 \%$ CI $[0.05,0.28]$. Desire for self-control did not significantly predict CDC adherence, $t(137)=1.69, p$ $=.093, b=0.14,95 \%$ CI $[-0.03,0.32]$; however, when controlling for trait self-control, state self-control, and social desirability, desire for self-control significantly predicted more CDC adherence, $t(137)=2.82, p=.006, b=0.20$, $95 \%$ CI $[0.73,0.42]$. The multiple regression for trait selfcontrol, state self-control, and desire for self-control predicting CDC Adherence is reported in Table 2.

\section{Stockpiling}

Trait self-control did not significantly predict stockpiling, $t(137)=1.36, p=.177, b=-0.12,95 \%$ CI $[-0.38,0.07]$. Conversely, state self-control significantly predicted less stockpiling, $t(137)=2.53, p=.012, b=-0.212,95 \% \mathrm{CI}$ $[-0.27,-0.03]$, even when controlling for social desirability, $t(137)=2.68, p=.008, b=-0.23,95 \%$ CI $[-0.28,-0.04]$. Desire for self-control did not significantly predict stockpiling, $t(137)=1.93, p=.056, b=0.17,95 \% \mathrm{CI}$ $[-.004,0.34]$. The multiple regression for trait self-control, state self-control, and desire for self-control predicting stockpiling is reported in Table 3.

\section{Discussion}

Study 1 found that trait and state self-control predicted more adherence to CDC recommendations, and state self-control 
Table 1 Means, SDs, and Zeroorder correlations among Study 1 variables

\begin{tabular}{llllllll}
\hline Variable & $M$ & $S D$ & 1 & 2 & 3 & 4 & 5 \\
\hline 1. Trait Self-Control & 3.44 & 0.67 & & & & \\
2. State Self-Control & 5.01 & 1.28 & $.64^{* * *}$ & & & \\
3. Desire for Self-Control & 3.59 & 0.87 & $-.30^{* * *}$ & $-.27^{* * *}$ & & \\
4. Stockpiling Behaviors & 4.74 & 0.90 & -.12 & $-.21^{*}$ & .16 & \\
5. CDC Adherence & 6.11 & 0.88 & $.21^{*}$ & $.26^{* *}$ & .14 & $.24 * *$ & \\
6. Social Desirability & 5.65 & 2.21 & $.34^{* * *}$ & $.24^{* *}$ & -.02 & .03 & .14 \\
\hline
\end{tabular}

Note. $\mathrm{CDC}=$ Centers for Disease Control and Prevention. $* p<.05, * * p<.01, * * * p<.001$ also predicted less stockpiling. These results suggest that individuals with low self-control were less likely to engage in behaviors that protect themselves and others from adverse effects during the pandemic than individuals with high selfcontrol. Moreover, with all self-control variables in the model, state self-control and desire for self-control predicted more CDC adherence, but trait self-control did not predict CDC adherence.

This suggests that trait self-control may be less relevant for predicting responses to time-specific events than current feelings of self-control.

\section{Study 2}

Study 2 tested the hypothesis that state self-control and desire for self-control would predict more CDC adherence, less stockpiling, and less hedonic behavior. Study 2 also tested the hypothesis that emotional uncertainty would predict more stockpiling and more hedonic behavior, whereas cognitive uncertainty would predict more CDC adherence. We also predicted that emotional uncertainty would be related to more stockpiling and indulgence in hedonic behavior for people low in state selfcontrol, but not for people high in state self-control. Specifically, Study 2 tested the hypothesis that state self-control would moderate the relationships between emotional uncertainty and stockpiling, and emotional uncertainty and hedonic behavior.

Table 2 Multiple regression predicting CDC adherence (Study 1)

\begin{tabular}{lllll}
\hline Variable & $t$ & $p$ & $b$ & $95 \%$ CI \\
\hline Trait Self-Control & 1.34 & .182 & 0.14 & {$[-.09, .46]$} \\
State Self-Control & 2.70 & .008 & 0.27 & {$[.05, .34]$} \\
Desire for Self-Control & 3.49 & .001 & 0.28 & {$[.13, .47]$} \\
\hline
\end{tabular}

Note . $\mathrm{CDC}=$ Centers for Disease Control and Prevention

\section{Method}

\section{Participants}

An a priori power analysis (GPower; Erdfelder et al., 1996) was used to determine the number of participants needed to detect a small-medium effect size for uncertainty on pandemic-related responses. Using $\alpha=.05$ (two-tailed), it was determined that a minimum of 191 participants were required to obtain an effect size of $r=.20$ in a correlation test with $80 \%$ power. We decided in advance to add $10 \%$ of this total for attrition to account for anticipated attrition due to completion and attention check failures $(N=210)$. U.S. residents were recruited for an online study via TurkPrime through Amazon's Mechanical Turk (MTurk; cf. Buhrmester et al., 2011; TurkPrime; Litman et al., 2017). Of the 210 participants recruited, 17 were excluded due to their failure on the attention check question embedded in the state self-control measure. Any participants with missing data for a certain measure were excluded (listwise) from the analyses for that measure. Analyses were performed on the final sample ( $N$ $=193 ; 66$ women, $121 \mathrm{men} ; M_{\text {age }}=36.34, S D=11.78$ ).

\section{Materials}

Adherence to CDC health recommendations, stockpiling behavior (see Appendix 3 for full measure), state self-control, desire for self-control were assessed with the same measures as in Study 1 (Cronbach's $\alpha: .86, .91, .94, .86$, respectively). We also measured responses to uncertainty and indulgence in hedonic behaviors.

Table 3 Multiple regression predicting stockpiling (Study 1)

\begin{tabular}{lllll}
\hline Variable & $t$ & $p$ & $b$ & $95 \%$ CI \\
\hline Trait Self-Control & 0.64 & .521 & 0.07 & {$[-.20, .38]$} \\
State Self-Control & 1.94 & .054 & -0.21 & {$[-.30, .003]$} \\
Desire for Self-Control & 1.82 & .071 & 0.15 & {$[-.01, .34]$} \\
\hline
\end{tabular}


Uncertainty Response Scale (URS; Greco \& Roger, 2001) The URS was designed to assess individual differences in coping with uncertainty. We used the emotional uncertainty factor and the cognitive uncertainty factor from the URS to measure differences in orientation toward uncertainty. The emotional uncertainty factor of the URS (URS-EU) was measured using a 15-item questionnaire, with anchors of 1 (Never) to 4 (Always). Sample items include, "I get worried when a situation is uncertain," and "Sudden changes make me feel upset"; Cronbach's $\alpha=.93$. The cognitive uncertainty factor of the URS (URS-CU) was measured using a 17-item questionnaire, with anchors of 1 (Never) to 4 (Always). Sample items include, "I like to plan ahead in detail rather than leaving things to chance," and, "I like to know exactly what I'm going to do next"; Cronbach's $\alpha=.89$.

Indulgence in Hedonic Behaviors Questionnaire Participants responded to a prompt that assessed activities they would engage in if they had extra free time: "Imagine you had a few extra hours of time after this study that you had not expected to have. How would you use that time?" Referencing their responses, participants then assessed how indulgent the activities were using a 6-item questionnaire on a 7-point scale, with anchors from 1 (Not very much) to 7 (Very much). Items include, "How satisfying are these activities?", "How desirable are these activities?", "How enjoyable are these activities", "How rewarding are these activities?", "How indulgent are these activities?", and "How luxurious are these activities?"; Cronbach's $\alpha=.78$.

\section{Procedure}

Following the same procedure as in Study 1, participants completed the stockpiling and CDC adherence questionnaires in a random order. Next, participants completed the state selfcontrol scale, desire for self-control scale, uncertainty response scale-emotional uncertainty, uncertainty response scale-cognitive uncertainty, and the indulgence measure in a random order, followed by the demographics questionnaire.

\section{Analytic Approach}

The Aiken and West (1991) method was used to test for interactions between emotional uncertainty and state selfcontrol on stockpiling and hedonic behavior using meancentered scores. Simple slopes were probed at one standard deviation above and below the mean of state self-control. Additional multiple regression analyses were conducted controlling for all three outcome measures: CDC adherence, stockpiling, and hedonic behavior. ${ }^{1}$ All analyses in Study 2

\footnotetext{
${ }^{1}$ Although these analyses were not pre-registered, we conducted them at the request of a reviewer.
}

were conducted in R (R Core Team, 2020) and figures were produced using the package 'rockchalk' (Johnson, 2019). We did not make any predictions for the relationship between emotional uncertainty and CDC behaviors, nor the relationship between cognitive uncertainty and stockpiling or hedonic behaviors, but we report these and all other exploratory results in Supplemental Materials, Fig. 1.

\section{Results}

Table 4 depicts means, standard deviations, and correlations for all variables.

\section{CDC Adherence}

State self-control did not significantly predict CDC adherence, $t(187)=0.52, p=.603, b=0.03,95 \%$ CI $[-0.08,0.14]$. Conversely, desire for self-control significantly predicted more CDC adherence, $t(187)=2.88, p=.004, b=0.27$, $95 \%$ CI $[0.09,0.46]$. Likewise, cognitive uncertainty significantly predicted more CDC adherence, $t(187)=5.75, p<$ $.001, b=0.73,95 \%$ CI $[0.48,0.98]$. The respective effects of state self-control, desire for self-control, and cognitive uncertainty on CDC adherence when controlling for stockpiling and indulgence in hedonic behavior are reported in Table 5.

\section{Stockpiling}

Whereas state self-control significantly predicted less stockpiling, $t(187)=-4.77, p<.001, b=-0.26,95 \% \mathrm{CI}$ $[-0.37,-0.15]$, desire for self-control significantly predicted more stockpiling, $t(187)=7.08, p<.001, b=0.62,95 \% \mathrm{CI}$ $[0.44,0.79]$. Likewise, emotional uncertainty significantly predicted more stockpiling, $t(187)=6.07, p<.001, b=$ $0.57,95 \%$ CI $[0.38,0.75]$. The respective effects of state self-control, desire for self-control, and cognitive uncertainty on stockpiling when controlling for CDC adherence and hedonic behavior are reported in Table 6 .

\section{Hedonic Behavior}

Whereas state self-control significantly predicted less hedonic behavior, $t(186)=-3.00, p=.003, b=-0.18,95 \%$ CI $[-0.30$, $-0.06]$, desire for self-control significantly predicted more hedonic behavior, $t(186)=4.25, p<.001, b=0.42,95 \% \mathrm{CI}$ $[0.23,0.62]$. Likewise, emotional uncertainty significantly predicted more hedonic behavior, $t(187)=2.42, p=.017, b$ $=0.26,95 \% \mathrm{CI}[0.05,0.47]$. The respective effects of state self-control, desire for self-control, and emotional uncertainty on hedonic behavior when controlling for CDC adherence and stockpiling are reported in Table 7. 
Fig. 1 CDC adherence between high and low state self-control. Note. CDC $=$ Centers for Disease Control and Prevention. Low $\mathrm{SSC}=-1$ standard deviation below the mean of state selfcontrol. High SSC $=+1$ standard deviation above the mean of state self-control

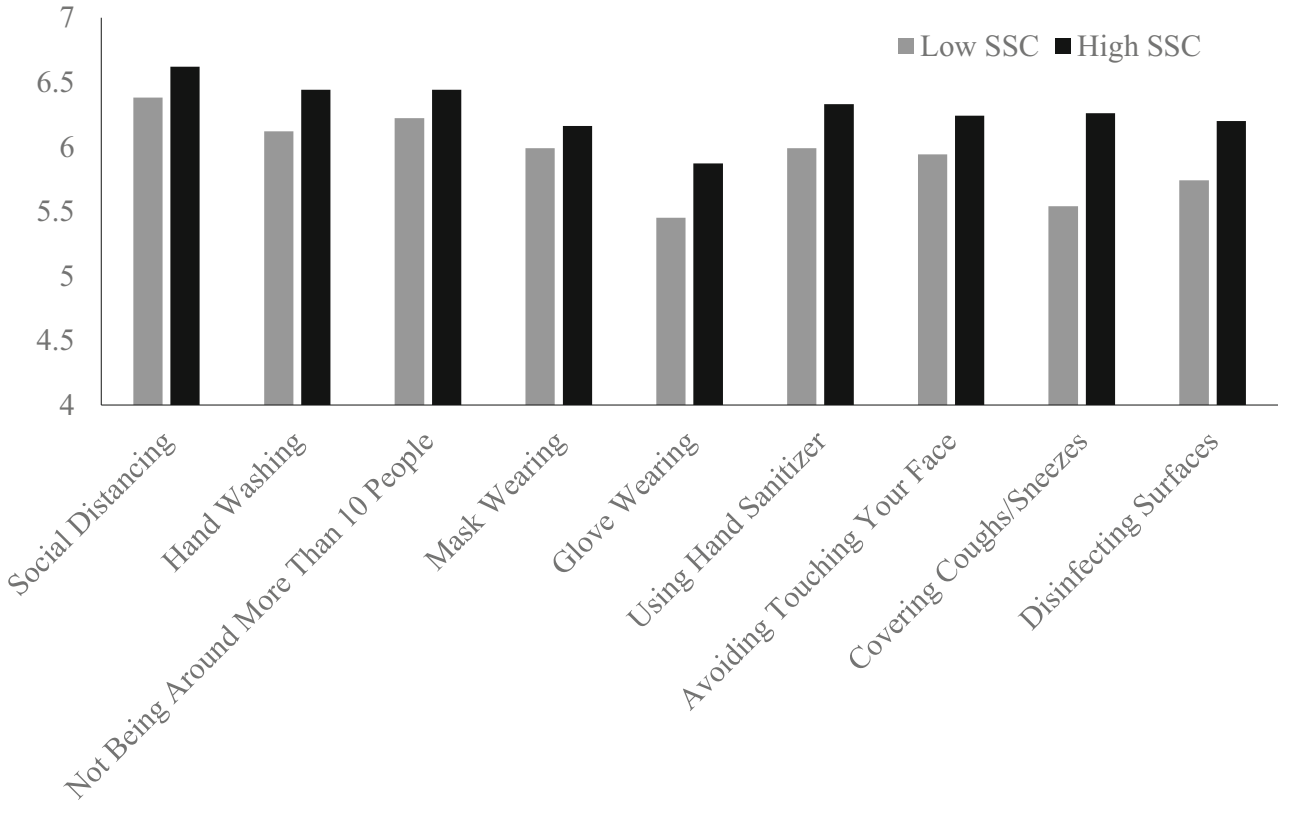

\section{Interaction between State Self-Control and Emotional Uncertainty}

There was a significant interaction between state self-control and emotional uncertainty on stockpiling, $t(184)=-4.69, p<$ $.001, b=-0.31,95 \%$ CI $[-0.44,-0.18]$, (Fig. 2). Specifically, among participants low in state self-control, emotional uncertainty significantly predicted more stockpiling, $t(184)=5.84$, $p<.001, b=0.65,95 \%$ CI [0.43, 0.87]; conversely, among participants high in state self-control, emotional uncertainty did not significantly predict stockpiling, $t(184)=0.26, p=$ $.795, b=0.03,95 \%$ CI $[-0.20,0.26]$.

There was also a significant interaction between state selfcontrol and emotional uncertainty on hedonic behavior, $t(184)$ $=-3.54, p<.001, b=-0.26,95 \%$ CI $[-0.49,-0.14]$ (Fig. 3). Specifically, among participants low in state self-control, emotional uncertainty predicted significantly more hedonic behavior, $t(184)=2.27 p=.025, b=0.28,95 \%$ CI $[0.04,0.51]$; conversely, among participants high in state self-control, emotional uncertainty did not significantly predict hedonic behavior, $t(184)=-1.85, p=.066, b=-0.24,95 \%$ CI $[-0.49,0.02]$.

\section{Discussion}

Replicating Study 1, Study 2 found that state self-control predicted less stockpiling; Study 2 additionally found that state self-control predicted less hedonic behavior. Also replicating Study 1, Study 2 found that that desire for self-control predicted more CDC adherence; Study 2 additionally found that desire for self-control predicted more stockpiling and hedonic behavior. Unlike Study 1, Study 2 found that state self-control predicted more $\mathrm{CDC}$ adherence only when controlling for the other outcome measures. This was not one of our pre-registered analyses and should be interpreted cautiously. Finally, as predicted, Study 2 found that cognitive uncertainty predicted more CDC adherence, whereas emotional uncertainty predicted more stockpiling and hedonic behavior. These results suggest that individual differences in self-control and cognitive responses to uncertainty are associated with differences in reported behavioral responses to the COVID-19 pandemic.

As predicted, Study 2 also found that state self-control moderated the effects of emotional uncertainty on stockpiling and on hedonic behavior, respectively. Specifically, Study 2 found
Table 4 Means, SDs, and Zeroorder correlations among Study 2 variables

\begin{tabular}{lllllllll}
\hline Variable & $M$ & $S D$ & 1 & 2 & 3 & 4 & 5 & 6 \\
\hline 1. Emotional Uncertainty & 2.45 & 0.68 & & & & & \\
2. Cognitive Uncertainty & 2.98 & 0.50 & $.24 * * *$ & & & & & \\
3. State Self-Control & 4.24 & 1.20 & $-.73^{* * *}$ & -.001 & & & \\
4. Desire for Self-Control & 3.71 & 0.71 & $.53^{* * *}$ & $.23^{* *}$ & $-.45^{* * *}$ & & & \\
5. Stockpiling Behaviors & 5.85 & 0.95 & $.40^{* * *}$ & $.32^{* * *}$ & $-.33^{* * *}$ & $.46^{* * *}$ & & \\
6. CDC Adherence & 5.71 & 0.95 & .07 & $.39^{* * *}$ & .04 & $.21^{* *}$ & $.50^{* * *}$ & \\
7. Hedonic Behaviors & 5.31 & 1.02 & $.17^{*}$ & $.33^{* * *}$ & $-.21^{* *}$ & $.30^{* * *}$ & $.49^{* * *}$ & $.21^{* *}$ \\
\hline
\end{tabular}

Note. $\mathrm{CDC}=$ Centers for Disease Control and Prevention. $* p<.05, * * p<.01, * * * p<.001$ 
Table 5 Main effects on CDC adherence controlling for stockpiling and hedonic behavior (Study 2)

\begin{tabular}{lllll}
\hline Variable & $t$ & $p$ & $b$ & $95 \%$ CI \\
\hline State Self-Control & 3.42 & .001 & 0.17 & {$[.08, .28]$} \\
Desire for Self-Control & -.39 & .698 & -0.04 & {$[-.23, .15]$} \\
Cognitive Uncertainty & 4.32 & .001 & 0.53 & {$[.29, .77]$} \\
\hline
\end{tabular}

Note. $\mathrm{CDC}=$ Centers for Disease Control and Prevention

that emotional uncertainty predicted more stockpiling and hedonic behavior among participants low in state self-control, but not among participants high in state self-control. These results suggest that state self-control plays a role in people's behavioral responses to the COVID-19 pandemic, but may interact with people's dispositional responses to uncertainty.

\section{General Discussion}

The present research found evidence that individual differences in self-control and cognitive response to uncertainty support compliance with guidelines during the COVID-19 global pandemic. Participants with high trait self-control were more likely to report following CDC behaviors, even when controlling for social desirability (Study 1). Participants with high state self-control were less likely to report stockpiling in response to the pandemic (Studies 1 and 2).

As predicted and pre-registered, self-control was associated with weaker effects of emotional uncertainty on behavior. The effects of emotional uncertainty on behavior were weaker for people with high state self-control than for people with low state self-control. For people with low state self-control, emotional responses to uncertainty predicted more stockpiling and hedonic behaviors. However, for people with high state selfcontrol, there was no relationship between emotional responses to uncertainty and stockpiling or hedonic behaviors.

The present research builds on previous research by showing that in addition to trait self-control, state levels of selfcontrol are associated with better guideline adherence. Selfcontrol not only plays a central role in these relationships, but it can also be associated with differences in the effect of traits on behavior. Our results contribute evidence to the theory that individual differences are more strongly associated with

Table 6 Main effects on stockpiling controlling for CDC adherence and hedonic behavior (Study 2)

\begin{tabular}{lllll}
\hline Variable & $t$ & $p$ & $b$ & $95 \% C I$ \\
\hline State Self-Control & -4.91 & .001 & -0.21 & {$[-.30,-.13]$} \\
Desire for Self-Control & 5.10 & .001 & 0.38 & {$[.24, .53]$} \\
Emotional Uncertainty & 6.05 & .001 & 0.44 & {$[.30, .59]$} \\
\hline
\end{tabular}

Note. $\mathrm{CDC}=$ Centers for Disease Control and Prevention
Table 7 Main effects on hedonic behavior controlling for CDC adherence and stockpiling (Study 2)

\begin{tabular}{lllll}
\hline Variable & $t$ & $p$ & $b$ & $95 \%$ CI \\
\hline State Self-Control & -0.80 & .422 & -0.05 & {$[-.17, .07]$} \\
Desire for Self-Control & 1.27 & .207 & 0.13 & {$[-.07, .33]$} \\
Emotional Uncertainty & -0.51 & .608 & -0.06 & {$[-.26, .16]$} \\
\hline
\end{tabular}

Note . $\mathrm{CDC}=$ Centers for Disease Control and Prevention

behaviors at low levels of self-control (Bertrams et al., 2013; Englert \& Bertrams, 2015; Tangney et al., 2004). Our findings show that the effect of emotional responses to uncertainty on reported behaviors is lower for those high in state self-control.

Desire for self-control involves the perception that one does not have enough self-control to meet demands, and is conceptually and statistically distinct from amount of self-control (Uziel \& Baumeister, 2017). Desire for self-control was correlated with higher CDC adherence in both studies, as well as stockpiling and engagement in hedonic behaviors in Study 2. The finding that desire for self-control was related to CDC adherence was opposite of our prediction; however, prior work has shown that desire for self-control is associated with a fear of failure, stronger prevention focus, and less emotional stability (Uziel et al., 2021). This suggests that those high in desire for self-control may be sensitive to threats, so threatening environments, such as a pandemic, may be a motivating factor to take action. Desire for self-control is also associated with increases in behavioral intentions, such as wanting to join a self-control training program (Uziel et al., 2021). Our findings suggest that desire for selfcontrol may be associated with a greater likelihood of acting to reduce uncertainty, whether that be by engaging in preventative health behaviors, stockpiling goods, or distracting oneself with a pleasurable activity. These studies provide support for the growing literature on the impact of wanting more self-control on efforts of self-control. Although prior work has shown a somewhat ironic effect of desire for self-control, in that wanting more self-control impaired future efforts of self-control (Uziel \& Baumeister, 2017), our results suggest that having a high desire for self-control in a threatening environment may be motivating enough to enact behaviors of self-control.

Although the uncertainty surrounding the pandemic is often presented as a negative, the present research suggests that greater awareness and response to uncertainty can be associated with greater compliance with following CDC recommendations. Participants with a greater cognitive response to uncertainty engaged in more CDC-recommended behaviors than participants who were less responsive to uncertainty. This fits with previous research showing that greater responsiveness to uncertainty was associated with more adaptive health behaviors, such as seeking out precautionary measures (Rosen \& Knäuper, 2009). Our findings emphasize the importance of having clear, applicable guidelines as a means to reduce 
Fig. 2 Relationship between emotional uncertainty and stockpiling behaviors by state self-control. Note. $\mathrm{SSC}=$ State Self-Control. Low SSC $=-1$ standard deviation below the mean of state self-control. High $\mathrm{SSC}=+1$ standard deviation above the mean of state selfcontrol

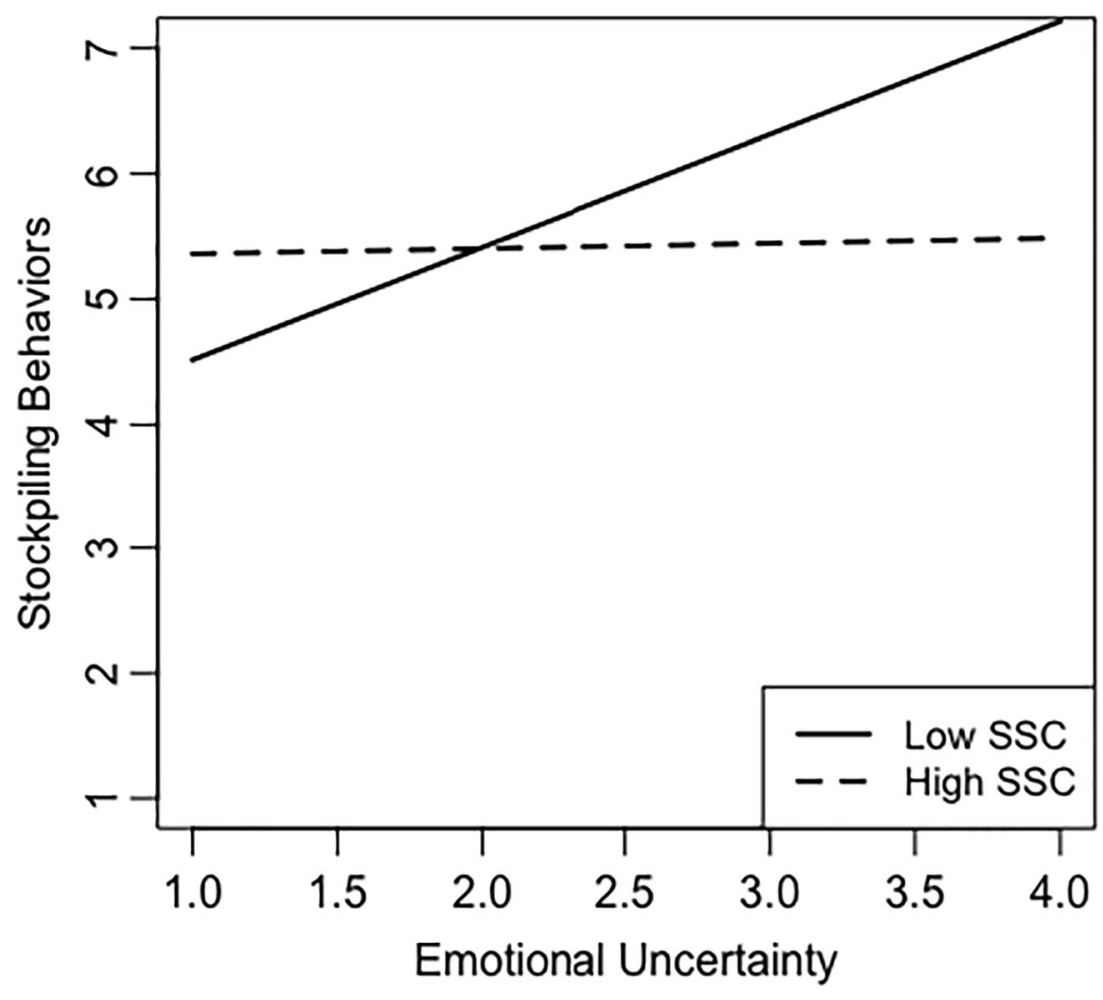

uncertainty. In both studies, CDC adherence and stockpiling were positively correlated. It is plausible that people high in emotional and cognitive uncertainty have different motivations for engaging in the same behaviors. For people with a strong emotional response to uncertainty, stockpiling and hedonic behaviors could be used to cope with the fear and uncertainty surrounding the pandemic. For people with a

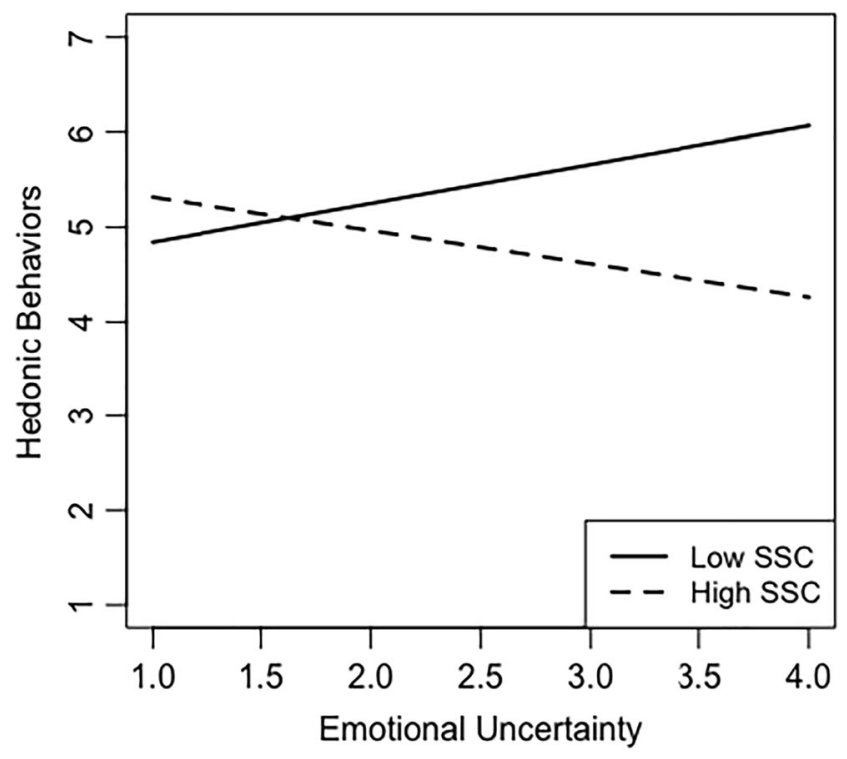

Fig. 3 Relationship between emotional uncertainty and hedonic behaviors by state self-control. Note. SSC = State Self-Control. Low $\mathrm{SSC}=-1$ standard deviation below the mean of state self-control. High $\mathrm{SSC}=+1$ standard deviation above the mean of state self-control cognitive response to uncertainty, stockpiling and engagement in hedonic behaviors may have been a method of coping through planned actions and strategies to reduce uncertainty. This interpretation is particularly relevant to the finding that a cognitive response to uncertainty was correlated with CDC behavior adherence, whereas an emotional response to uncertainty was not. When faced with uncertainty, an individual with a cognitive response may be more likely to take effortful actions, such as following CDC-recommended health behaviors, to manage the uncertainty of a situation. Thus, our findings contribute to the body of literature showing that differences in responses to uncertainty can lead to specific coping behaviors, particularly related to health domains (Brouwers \& Sorrentino, 1993; Greco \& Roger, 2001; Hillen et al., 2017).

\section{Limitations}

Because our results are purely correlational, we cannot determine the causal direction of these relationships. As such, our results should not be interpreted to mean that self-control is necessarily the cause of decreased stockpiling behaviors and increased adherence to CDC recommendations. For example, it is possible that feeling like one is successfully enacting behaviors to deal with the pandemic may make a person feel more confident in their self-control abilities. Additionally, previous research shows that people who have more self-control have more extrinsically successful careers, marked by higher salaries and more occupational prestige, as well as higher relationship and parenting satisfaction (Converse et al., 2018). 
Additionally, those in higher income communities were more likely to follow CDC recommendations on social distancing and sheltering in place (Weill et al., 2020). These resources may have made it more possible for people with high selfcontrol to adapt to recommendations to stay home. However, Study 1 found significant differences between people high and low in self-control in behaviors that seem unlikely to be affected by resources, such as covering coughs and sneezes. This suggests that self-control is associated with better adherence in the context of a pandemic.

The present findings are based on an MTurk sample of U.S. residents. Although there have been concerns over quality of data obtained from online markets, research suggests that MTurk data are valid and comparable with data collected through traditional laboratory settings (Buhrmester et al., 2011). Including only American residents allowed us to limit (though admittedly not eliminate) the differences in external constraints, which could potentially change the influence of self-control on compliance behaviors. However, in limiting our sample to only American residents, we cannot generalize these results to other populations. For example, in countries with strongly enforced requirements (Think Global Health, 2020), there may be less variability in behavior that could be predicted by self-control. Another limitation is that the effect sizes are small to medium, suggesting that other factors certainly play a role in predicting these behaviors. Another limitation is that CDC behavior adherence was measured by self-report, rather than an objective behavioral measure. Although we controlled for social desirability in Study 1, self-reported behaviors may not be as accurate as observable measures (O Boyle et al., 2001).

\section{Implications and Future Directions}

To the extent that self-control supports people's ability to adhere to recommendations, interventions that increase the likelihood of success at self-control may be used to increase compliance with these recommendations. Implementation intentions, for example, involve a plan to engage in certain behaviors in a given situation, which diminishes the need to use self-control (Webb \& Sheeran, 2003). Implementation intentions have shown to be effective in promoting self-control abilities in the initiation of health-protective, disease-preventive, and prosocial behaviors (Gollwitzer \& Sheeran, 2006). An implementation intention plan one could use involves linking a behavior with a situational context, such as, "if I leave the house, I will wear a mask."

In a similar vein, habits are a reliance on automatic behaviors that require less self-control than effortful behaviors. By making a habit of always keeping a mask or hand sanitizer in one's car or on one's body, one will not have to think about bringing it with them, relieving the need for effortful control in future occurrences. Planning ahead and forming good habits serve to both reduce the need for self-control and offset low self-control in the moment. Regularly practicing such good habits and plans can even improve self-control abilities in the long run (Baumeister et al., 2006; Tian et al., 2018), which could serve to benefit self-control during a time when it is most needed. Kokkoris and Stavrova (2021) found that in the context of goal pursuit during the pandemic, high trait self-control was associated with the development of new goal-directed behaviors, as well as those behaviors becoming habits. This suggests that high self-control is resilient to disruptive circumstances and can facilitate positive behavioral change even in adverse contexts.

In the context of the pandemic, the effects of a dispositional emotional response to uncertainty were stronger for those with low state self-control. Although prior research has examined the relationship between depleted self-control and the effects of select traits on behavior, future research should expand upon self-control's moderating effects on dispositional responses and coping mechanisms. Our hypothesis was based on the idea that an emotional response to uncertainty predicts maladaptive behaviors (Greco \& Roger, 2001; Van den Bos et al., 2007). However, it is possible that, for people low in state self-control, an emotional response to uncertainty may predict greater likelihood of taking whatever action is available, including beneficial ones. This fits with research showing that people sometimes show a reactive approach response to uncertainty (McGregor et al., 2010). Nash et al. (2011) found that uncertainty increases people's motivation to enact approach behaviors that reduce distress. Additional research would be needed to determine if a reactive approach response to uncertainty is greater when state self-control is low.

\section{Conclusion}

The present research provides evidence that self-control and dispositional responses to uncertainty are related to engaging in stockpiling and in behaviors that reduce the spread of a virus during a time of global pandemic. Individuals low in trait self-control and low in cognitive responses to uncertainty are less likely to follow health guidelines. Individuals low in state self-control and individuals high in cognitive or emotional responses to uncertainty are more likely to stockpile goods, leaving shelves empty for future shoppers, than those high in state self-control or low in cognitive and emotional responses to uncertainty. Knowing that a cognitive response to uncertainty involves a plan to take action, guidance and recommendations from governing bodies regarding health behaviors should include clear, actionable steps one can take to protect oneself and minimize the spread of a virus. Following set guidelines might make people less susceptible to fluctuations in self-control or responses to uncertainty in uncertain circumstances. Immediately enacting well-defined public guidelines in ambiguous situations could also potentially eliminate the 
need for state self-control to act as a protective moderator on the effects of emotional uncertainty. Policy-makers and health experts should take into account individual differences in un- certainty responses and self-control that may hinder or enhance voluntary compliance with health and societal recommendations.

\section{Appendix 1}

\section{CDC Behavior Adherence Measure Items in Study 1}

Instructions: Using the scale provided, indicate how much you have done each of the following activities since, or in response to, the outbreak of COVID-19 (the novel coronavirus).

\begin{tabular}{|c|c|c|c|c|c|c|c|c|}
\hline & $\begin{array}{l}\text { Less than } \\
\text { usual }\end{array}$ & & & $\begin{array}{l}\text { Usual } \\
\text { amount }\end{array}$ & & & $\begin{array}{l}\text { More than } \\
\text { usual }\end{array}$ & N/A \\
\hline Social distancing & $\circ$ & $\circ$ & $\circ$ & $\circ$ & $\circ$ & $\circ$ & $\circ$ & $\circ$ \\
\hline Washing your hands & $\circ$ & $\circ$ & $\circ$ & $\circ$ & $\circ$ & $\circ$ & $\circ$ & $\circ$ \\
\hline Not being around more than 10 people & $\circ$ & $\circ$ & $\circ$ & $\circ$ & $\circ$ & $\circ$ & $\circ$ & $\circ$ \\
\hline Wearing cloth/medical masks & $\circ$ & $\circ$ & $\circ$ & $\circ$ & $\circ$ & $\circ$ & $\circ$ & $\circ$ \\
\hline Wearing rubber gloves & $\circ$ & $\circ$ & $\circ$ & $\circ$ & $\circ$ & $\circ$ & $\circ$ & $\circ$ \\
\hline Using hand sanitizer & $\circ$ & $\circ$ & $\circ$ & $\circ$ & $\circ$ & $\circ$ & $\circ$ & $\circ$ \\
\hline Avoiding touching your face & $\circ$ & $\circ$ & $\circ$ & $\circ$ & $\circ$ & $\circ$ & $\circ$ & $\circ$ \\
\hline Covering coughs/sneezes & $\circ$ & $\circ$ & $\circ$ & $\circ$ & $\circ$ & $\circ$ & $\circ$ & $\circ$ \\
\hline Disinfecting surfaces & ○ & ○ & $\circ$ & o & $\circ$ & o & ○ & o \\
\hline
\end{tabular}

\section{Appendix 2}

\section{Stockpiling Behaviors Measure Items in Study 1}

Instructions: Using the sliders below, indicate how much of each product you have bought since, or in response to, the outbreak of COVID-19 (the novel coronavirus).

\begin{tabular}{|c|c|c|c|c|c|c|c|c|}
\hline & $\begin{array}{l}\text { Less than } \\
\text { usual }\end{array}$ & & & $\begin{array}{l}\text { Usual } \\
\text { amount }\end{array}$ & & & $\begin{array}{l}\text { More than } \\
\text { usual }\end{array}$ & N/A \\
\hline Toilet paper & $\circ$ & $\circ$ & $\circ$ & $\circ$ & $\circ$ & $\circ$ & $\circ$ & $\circ$ \\
\hline Meat & $\circ$ & $\circ$ & ० & $\circ$ & $\circ$ & $\circ$ & $\circ$ & $\circ$ \\
\hline Eggs & $\circ$ & $\circ$ & $\circ$ & $\circ$ & $\circ$ & $\circ$ & $\circ$ & $\circ$ \\
\hline Bread & $\circ$ & $\circ$ & $\circ$ & $\circ$ & $\circ$ & $\circ$ & $\circ$ & $\circ$ \\
\hline Canned Food & $\circ$ & $\circ$ & $\circ$ & $\circ$ & $\circ$ & $\circ$ & $\circ$ & $\circ$ \\
\hline Frozen Food & $\circ$ & $\circ$ & $\circ$ & $\circ$ & $\circ$ & $\circ$ & $\circ$ & $\circ$ \\
\hline Cleaning Products & $\circ$ & $\circ$ & $\circ$ & $\circ$ & $\circ$ & $\circ$ & $\circ$ & $\circ$ \\
\hline Medical Masks & $\circ$ & $\circ$ & $\circ$ & $\circ$ & $\circ$ & $\circ$ & $\circ$ & $\circ$ \\
\hline Rubber Gloves & $\circ$ & $\circ$ & $\circ$ & $\circ$ & $\circ$ & $\circ$ & $\circ$ & $\circ$ \\
\hline Board games/ video games/ puzzles & $\circ$ & $\circ$ & $\circ$ & $\circ$ & $\circ$ & $\circ$ & $\circ$ & $\circ$ \\
\hline Other recreational items & $\circ$ & $\circ$ & ० & $\circ$ & $\circ$ & $\circ$ & $\circ$ & $\circ$ \\
\hline Firearms & $\circ$ & ○ & $\circ$ & $\circ$ & $\circ$ & $\circ$ & $\circ$ & $\circ$ \\
\hline Ammunition & 0 & 0 & 0 & 0 & 0 & 0 & $\circ$ & 0 \\
\hline
\end{tabular}




\section{Appendix 3}

\section{Stockpiling Behaviors Measure Items in Study 2}

Instructions: Using the scale provided, indicate how much of each product you have bought since, or in response to, the outbreak of COVID-19 (the novel coronavirus).

\begin{tabular}{|c|c|c|c|c|c|c|c|c|}
\hline & $\begin{array}{l}\text { Less than } \\
\text { usual }\end{array}$ & & & $\begin{array}{l}\text { Usual } \\
\text { amount }\end{array}$ & & & $\begin{array}{l}\text { More than } \\
\text { usual }\end{array}$ & N/A \\
\hline Canned food & $\circ$ & ○ & $\circ$ & $\circ$ & $\circ$ & ○ & $\circ$ & $\circ$ \\
\hline Cleaning products & $\circ$ & ○ & $\circ$ & $\circ$ & $\circ$ & $\circ$ & $\circ$ & $\circ$ \\
\hline Toilet paper & $\circ$ & ○ & $\circ$ & $\circ$ & $\circ$ & $\circ$ & $\circ$ & $\circ$ \\
\hline Frozen food & $\circ$ & ० & $\circ$ & $\circ$ & $\circ$ & $\circ$ & $\circ$ & $\circ$ \\
\hline $\begin{array}{l}\text { Masks/Cloth face coverings } \\
\text { (including supplies to make them) }\end{array}$ & $\circ$ & ○ & $\circ$ & $\circ$ & $\circ$ & $\circ$ & $\circ$ & $\circ$ \\
\hline Rubber/ Medical gloves & $\circ$ & ○ & ○ & $\circ$ & $\circ$ & $\circ$ & $\circ$ & $\circ$ \\
\hline Perishable foods & $\circ$ & $\circ$ & $\circ$ & $\circ$ & ○ & $\circ$ & $\circ$ & $\circ$ \\
\hline Firearms and/or Ammunition & $\circ$ & ○ & $\circ$ & $\circ$ & $\circ$ & $\circ$ & $\circ$ & $\circ$ \\
\hline Over-the-counter medicine & $\circ$ & $\circ$ & $\circ$ & $\circ$ & ○ & $\circ$ & $\circ$ & $\circ$ \\
\hline Entertainment items & $\circ$ & ○ & ○ & $\circ$ & ○ & $\circ$ & $\circ$ & $\circ$ \\
\hline Hand soap/ sanitizer & $\circ$ & $\circ$ & $\circ$ & $\circ$ & $\circ$ & ○ & $\circ$ & $\circ$ \\
\hline Personal care/ grooming items & $\circ$ & o & $\circ$ & $\circ$ & $\circ$ & $\circ$ & $\circ$ & $\circ$ \\
\hline
\end{tabular}

Supplementary Information The online version contains supplementary material available at https://doi.org/10.1007/s12144-021-02066-y.

Funding This work was supported by a grant from the Binational Science Foundation (BSF; Proposal \#2016044).

Data Availability Study 2 is pre-registered at https://aspredicted.org/ blind.php? $\mathrm{x}=\mathrm{d} 2 \mathrm{j} 24 \mathrm{k}$; https://aspredicted.org/x 4hi5.pdf. The datasets analyzed during the current studies are available from the corresponding author on request.

\section{Declarations}

\section{Conflict of Interest None}

Ethics Approval All procedures performed in studies involving human participants were in accordance with the ethical standards of the institutional and/or national research committee and with the 1964 Helsinki declaration and its later amendments or comparable ethical standards.

Consent to Participate Informed consent was obtained from all individual participants included in the study.

Credit Statement Jordan E. Rodriguez: Conceptualization, Data curation, Formal analysis, Investigation, Methodology, Project administration, Visualization, Writing - original draft, review \& editing.

Hayden L. Holmes: Conceptualization, Data curation, Formal analysis, Investigation, Methodology, Visualization, Writing - original draft, review \& editing.
Jessica L. Alquist: Conceptualization, Funding acquisition, Methodology, Supervision, Visualization, Writing - original draft, review \& editing.

Liad Uziel: Funding acquisition, Writing - review \& editing.

Alec J. Stinnett: Writing - review \& editing.

\section{References}

Ahir, H., Bloom, N., \& Furceri, D. (2020, April 4). Global uncertainty related to Coronavirus at a record high. IMFBlog. https://blogs.imf. org/2020/04/04/global-uncertainty-related-to-coronavirus-atrecord-high/

Aiken, L. S., \& West, S. G. (1991). Multiple regression: Testing and interpreting interactions. Sage.

Anderson, E. C., Carleton, R. N., Diefenbach, M., \& Han, P. K. J. (2019). The relationship between uncertainty and affect. Frontiers in Psychology, 10, 2504. https://doi.org/10.3389/fpsyg.2019.02504.

Baumeister, R. F., \& Heatherton, T. F. (1996). Self-regulation failure: An overview. Psychological Inquiry, 7(1), 1-15.

Baumeister, R. F., Gailliot, M., DeWall, C. N., \& Oaten, M. (2006). Selfregulation and personality: How interventions increase regulatory success, and how depletion moderates the effects of traits on behavior. Journal of Personality, 74, 1773-1801.

Bertrams, A., Englert, C., Dickhäuser, O., \& Baumeister, R. F. (2013). Role of self-control strength in the relation between anxiety and cognitive performance. Emotion, 13(4), 668-680. https://doi.org/ 10.1037/a0031921.

Brooks, S. K., Webster, R. K., Smith, L. E., Woodland, L., Wessely, S., \& Greenberg, N. (2020). The psychological impact of quarantine and 
how to reduce it: Rapid review of the evidence. The Lancet, 395(10227), 912-920.

Brouwers, M. C., \& Sorrentino, R. M. (1993). Uncertainty orientation and protection motivation theory: The role of individual differences in health compliance. Journal of Personality and Social Psychology, 65(1), 102-112.

Buhrmester, M., Kwang, T., \& Gosling, S. D. (2011). Amazon's mechanical Turk: A new source of inexpensive, yet high-quality, data? Perspectives on Psychological Science, 6, 3-5. https://doi.org/10. 1177/1745691610393980.

Centers for Disease Control and Prevention. (2020a). Coronavirus disease 2019 (COVID-19): How to protect yourself \& others. Retrieved April 2, 2020 from https://www.cdc.gov/coronavirus/ 2019-ncov/prevent-getting-sick/prevention.html

Centers for Disease Control and Prevention. (2020b). Coronavirus disease 2019 (COVID-19): Coping with stress. Retrieved February 22, 2021, from https://www.cdc.gov/coronavirus/2019-ncov/daily-lifecoping/managing-stress-anxiety.html

Converse, P. D., Beverage, M. S., Vaghef, K., \& Moore, L. S. (2018). Self-control over time: Implications for work, relationship, and wellbeing outcomes. Journal of Research in Personality, 73, 82-92.

Crescioni, W. A., Ehrlinger, J., Alquist, J. L., Conlon, K. E., Baumeister, R. F., Schatschneider, C., \& Dutton, G. R. (2011). High trait selfcontrol predicts positive health behaviors and success in weight loss. Journal of Health Psychology, 16(5), 750-759. https://doi.org/10. 1177/1359105310390247.

de Ridder, D. T. D., Lensvelt-Mulders, G., Finkenauer, C., Stok, F. M., \& Baumeister, R. F. (2012). Taking stock of self-control: A metaanalysis of how trait self-control relates to a wide range of behaviors. Personality and Social Psychology Review, 16, 76-99. https://doi. org/10.1177/1088868311418749.

de Ridder, D. T. D., Kroese, F. M., \& Gillebaart, M. (2018). Whatever happened to self-control? A proposal for integrating notions from trait self-control studies into state self-control research. Motivation Science, 4, 39-49.

DeWall, C. N., Baumeister, R. F., Gailliot, M. T., \& Maner, J. K. (2008). Depletion makes the heart grow less helpful: Helping as a function of self-regulatory energy and genetic relatedness. Personality and Social Psychology Bulletin, 34(12), 1653-1662.

Englert, C., \& Bertrams, A. (2015). Integrating attentional control theory and the strength model of self-control. Frontiers in Psychology, 6, 824. https://doi.org/10.3389/fpsyg.2015.00824.

Erdfelder, E., Faul, F., \& Buchner, A. (1996). GPOWER: A general power analysis program. Behavior Research Methods, Instruments, \& Computers, 28, 1-11. https://doi.org/10.3758/ BF03203630.

Executive Order No. 13910, 85 FR 17001. (2020). https://www. federalregister.gov/documents/2020/03/26/2020-06478/preventinghoarding-of-health-and-medical-resources-to-respond-to-thespread-of-covid-19

Fujita, K. (2011). On conceptualizing self-control as more than the effortful inhibition of impulses. Personality and Social Psychology Review, 15(4), 352-366. https://doi.org/10.1177/ 1088868311411165.

Gollwitzer, P. M., \& Sheeran, P. (2006). Implementation intentions and goal achievement: A meta-analysis of effects and processes. Advances in Experimental Social Psychology, 38, 69-119.

Gran, B. (2020, April 3). COVID-19 self-care: 7 ways to indulge yourself without breaking the budget. Forbes. https://www.forbes.com/sites/ advisor/2020/04/03/covid-19-self-care-7-ways-to-indulge-yourselfwithout-breaking-the-budget/?sh=1bc608e 54d67

Greco, V., \& Roger, D. (2001). Coping with uncertainty: The construction and validation of a new measure. Personality and Individual Differences, 31, 519-553.

Guynn, J. (2020, April 9). Looking for Lysol spray and Clorox wipes? COVID-19 wiped out disinfectants, but here's when you can buy again. USA Today. https://www.usatoday.com/story/money/2020/ 04/09/coronavirus-clorox-lysol-shortages-walmart-costco-publixwinco-lowes/2961818001/

Hagger, M. S., Wood, C., Stiff, C., \& Chatzisarantis, N. L. (2009). The strength model of self-regulation failure and health-related behaviour. Health Psychology Review, 3(2), 208-238.

Hillen, M. A., Gutheil, C. M., Strout, T. D., Smets, E. M., \& Han, P. K. (2017). Tolerance of uncertainty: Conceptual analysis, integrative model, and implications for healthcare. Social Science \& Medicine, 180, 62-75.

Johnson, P. E. (2019). Rockchalk: Regression estimation and presentation. R package version 1.8.144. https://CRAN.R-project.org/ package $=$ rockchalk

Jones, C., \& Tyko, K. (2020, March 13). Preparing for the coronavirus: Shoppers are finding empty shelves, long lines at stores nationwide. USA Today. https://www.usatoday.com/story/money/2020/03/13/ coronavirus-toilet-paper-selling-out-costco-walmart-target/ 5041064002/

Kokkoris, M. D., \& Stavrova, O. (2021). Staying on track in turbulent times: Trait self-control and goal pursuit during self-quarantine. Personality and Individual Differences, 170, 110454. https://doi. org/10.1016/j.paid.2020.110454.

Lazarus, R. S., \& Folkman, S. (1984). Stress, appraisal, and coping. Springer Publishing Company.

Li, J., Yang, A., Dou, K., \& Cheung, R. Y. M. (2020a). Self-control moderates the association between perceived severity of the coronavirus disease 2019 (COVID-19) and mental health problems among the Chinese public. https://doi.org/10.31234/osf.io/2xadq

Li, M., Zhao, T., Huang, E., \& Li, J. (2020b). How does a public health emergency motivate People's impulsive consumption? An empirical study during the COVID-19 outbreak in China. International Journal of Environmental Research and Public Health, 17(14). https://doi.org/10.3390/ijerph17145019.

Litman, L., Robinson, J., \& Abberbock, T. (2017). TurkPrime.com: A versatile crowdsourcing data acquisition platform for the behavioral sciences. Behavior Research Methods, 49(2), 433-442. https://doi. org/10.3758/s13428-016-0727-z.

Mandel, N., Rucker, D. D., Levav, J., \& Galinsky, A. D. (2017). The compensatory consumer behavior model: How self-discrepancies drive consumer behavior. Journal of Consumer Psychology, 27, 133-146. https://doi.org/10.1016/j.jcps.2016.05.003.

Martarelli, C. S., \& Wolff, W. (2020). Too bored to bother? Boredom as a potential threat to the efficacy of pandemic containment measures. Humanities and Social Sciences Communications, 7(28). https://doi. org/10.1057/s41599-020-0512-6.

McGregor, I., Nash, K., Mann, N., \& Phills, C. E. (2010). Anxious uncertainty and reactive approach motivation (RAM). Journal of Personality and Social Psychology, 99(1), 133-147.

Nash, K., McGregor, I., \& Prentice, M. (2011). Threat and defense as goal regulation: From implicit goal conflict to anxious uncertainty, reactive approach motivation, and ideological extremism. Journal of Personality and Social Psychology, 101(6), 1291-1301.

National Safety Council. (2020). Odds of dying. Injury Facts. https:// injuryfacts.nsc.org/all-injuries/preventable-death-overview/odds-ofdying/

Nowak, B., Brzóska, P., Piotrowski, J., Sedikides, C., ŻemojtelPiotrowska, M., \& Jonason, P. K. (2020). Adaptive and maladaptive behavior during the COVID-19 pandemic: The roles of dark triad traits, collective narcissism, and health beliefs. Personality and Individual Differences, 167, 110232. https://doi.org/10.1016/j.paid. 2020.110232.

O'Boyle, C. A., Henly, S. J., \& Larson, E. (2001). Understanding adherence to hand hygiene recommendations: The theory of planned behavior. American Journal of Infection Control, 29(6), 352-360. 
Oppel, R. A. Jr. (2020, March 16). For some buyers with virus fears, the priority isn't toilet paper. It's guns. The New York Times. https:// www.nytimes.com/2020/03/16/us/coronavirus-gun-buyers.html

Pomerance, J., Light, N., \& Williams, L. E. (2020). In these uncertain times: Fake news amplifies the desires to save and spend in response to COVID-19. Journal of the Association for Consumer Research. https://doi.org/10.1086/711836.

R Core Team. (2020). R: A language and environment for statistical computing. R Foundation for Statistical Computing, Vienna, Austria. https://www.R-project.org/

Rosen, N. O., \& Knäuper, B. (2009). A little uncertainty goes a long way: State and trait differences in uncertainty interact to increase information seeking but also increase worry. Health Communication, 24(3), 228-238.

Rosen, N. O., Ivanova, E., \& Knäuper, B. (2014). Differentiating intolerance of uncertainty from three related but distinct constructs. Anxiety, Stress, and Coping, 27(1), 55-73. https://doi.org/10.1080/ 10615806.2013.815743.

Strahan, R., \& Gerbasi, K. C. (1972). Short, homogeneous versions of the Marlowe-Crowne social desirability scale. Journal of Clinical Psychology, 28(2), 191-193.

Tangney, J. P., Baumeister, R. F., \& Boone, A. L. (2004). High selfcontrol predicts good adjustment, less pathology, better grades, and interpersonal success. Journal of Personality, 72(2), 271-324.

Think Global Health (2020). Timeline of the Coronavirus. Retrieved June 2020 from https://www.thinkglobalhealth.org/article/updatedtimeline-coronavirus

Tian, A. D., Schroeder, J., Häubl, G., Risen, J. L., Norton, M. I., \& Gino, F. (2018). Enacting rituals to improve self-control. Journal of Personality and Social Psychology, 114(6), 851-876.

Tull, M. T., Barbano, A. C., Scamaldo, K. M., Richmond, J. R., Edmonds, K. A., Rose, J. P., \& Gratz, K. L. (2020). The prospective influence of COVID-19 affective risk assessments and intolerance of uncertainty on later dimensions of health anxiety. Journal of Anxiety Disorders, 75, 102290.

Twenge, J., Muraven, M., \& Tice, D. (2004). Measuring state self-control: Reliability, validity, and correlations with physical and psychological stress. Monmouth University unpublished.

Uziel, L., \& Baumeister, R. F. (2017). The self-control irony: Desire for self-control limits exertion of self-control in demanding settings. Personality and Social Psychology Bulletin, 43(5), 693-705. https://doi.org/10.1177/0146167217695555.

Uziel, L., Baumeister, R. F., \& Alquist, J. L. (2021). What makes people want more self-control: A duo of deficiency and necessity.
Motivation Science. Advance online publication. https://doi.org/10. 1037/mot0000213.

Van Den Bos, K., Euwema, M. C., Poortvliet, P. M., \& Maas, M. (2007). Uncertainty management and social issues: Uncertainty as an important determinant of reactions to socially deviating people. Journal of Applied Social Psychology, 37(8), 1726-1756.

Vohs, K. D., \& Baumeister, R. F. (Eds.). (2017). Handbook of self-regulation: Research, theory, and applications (3rd ed.). Guilford Press.

Webb, T. L., \& Sheeran, P. (2003). Can implementation intentions help to overcome ego-depletion? Journal of Experimental Social Psychology, 39(3), 279-286.

Weill, J. A., Stigler, M., Deschenes, O., \& Springborn, M. R. (2020). Social distancing responses to COVID-19 emergency declarations strongly differentiated by income. Proceedings of the National Academy of Sciences, 117(33), 19658-19660.

Wolff, W., \& Martarelli, C. S. (2020). Bored into depletion? Toward a tentative integration of perceived self-control exertion and boredom as guiding signals for goal-directed behavior. Perspectives on Psychological Science, 15(5), 1272-1283. https://doi.org/10.1177/ 1745691620921394

Wolff, W., Martarelli, C. S., Schüler, J., \& Bieleke, M. (2020). High boredom proneness and low trait self-control impair adherence to social distancing guidelines during the COVID-19 pandemic. International Journal of Environmental Research and Public Health, 17(15), 5420. https://doi.org/10.3390/ijerph1715542.

World Health Organization (WHO). (2020). Timeline of WHO 's response to COVID-19. Retrieved June 2020 from: https://www. who.int/news-room/detail/29-06-2020-covidtimeline

Xiong, J., Lipsitz, O., Nasri, F., Lui, L. M., Gill, H., Phan, L., ... \& McIntyre, R. S. (2020). Impact of COVID-19 pandemic on mental health in the general population: A systematic review. Journal of Affective Disorders, 277, 55-64. https://doi.org/10.1016/j.jad.2020. 08.001 .

Zhang, C., Smolders, K. C., Lakens, D., \& IJsselsteijn, W. A. (2018). Two experience sampling studies examining the variation of selfcontrol capacity and its relationship with core affect in daily life. Journal of Research in Personality, 74, 102-113. https://doi.org/10. 1016/j.jrp.2018.03.001.

Publisher's Note Springer Nature remains neutral with regard to jurisdictional claims in published maps and institutional affiliations. 